\title{
CONFIDENCE overview of improvements in radioecological human food chain models and future needs
}

\author{
N.A. Beresford ${ }^{1, *}$, C.L. Barnett ${ }^{1}$, J. Chaplow ${ }^{1}$, S. Lofts $^{1}$, C. Wells ${ }^{1}$, J.E. Brown ${ }^{2}$, A. Hosseini ${ }^{2}$, \\ H. Thørring ${ }^{2}$, T. Almahayni ${ }^{3}$, L. Sweeck ${ }^{3}$, J. Guillén ${ }^{4}$, O.-C. Lind ${ }^{5}$, D.H. Oughton ${ }^{5}$, B. Salbu ${ }^{5}$, \\ H.-C. Teien ${ }^{5}$, D.Perez- Sánchez ${ }^{6}$ and A. Real ${ }^{6}$ \\ ${ }^{1}$ UKCEH - UK Centre for Ecology \& Hydrology, Lancaster, UK. \\ 2 DSA - Norwegian Radiation and Nuclear Safety Authority, Østerås, Norway. \\ 3 SCK-CEN - Belgian Nuclear Research Centre, Mol, Belgium. \\ ${ }^{4}$ LARUEX - University of Extremadura, Cáceres, Spain. \\ 5 NMBU/CERAD - Norwegian University of Life Sciences, Centre for Environmental Radioactivity, Ås, Norway. \\ ${ }^{6}$ CIEMAT - Centro de Investigaciones Energéticas, Medioambientales y Tecnológicas, Madrid, Spain.
}

\begin{abstract}
Radioecological models used to make predictions of the radionuclide activity concentrations in human foodstuffs must be sufficiently robust and fit for purpose with uncertainties reduced where practicable. The CONFIDENCE project had a work package with the objective to improve the capabilities of radioecological models and this paper presents the key findings of this work. Recommendations for future radioecological studies/model developments are made based on the findings of the work conducted and consultations with end-users.
\end{abstract}

Keywords: food chain / radioactive particles / caesium $/{ }^{131} \mathrm{I} /{ }^{90} \mathrm{Sr}$

\section{Introduction}

There are considerable uncertainties associated with the radioecological simulation models used to predict the transfer of radionuclides along food chains. Initially after an accidental release, the factors determining the contamination of foodstuffs will largely be defined by vegetation interception and the time of year. During the transition phase, factors controlling the uptake of radionuclides to vegetation from soil will become more important and these will dominate during the long-term rehabilitation phase. However, predictions made using radioecological models may be used in the early part of the transition phase to make longer-term decisions, such as those associated with remediation strategies. Therefore, models must be sufficiently robust and fit for purpose with uncertainties reduced where practicable. A classic example of where predictions were made using models/information not fit for purpose is the post-Chernobyl case in upland United Kingdom. In 1986, it was stated that restrictions on sheep management because of high radiocaesium levels following the Chernobyl accident would last for a matter of weeks (Wynne 1992). However, restrictions remained in place until 2012.

*Corresponding author: nab@ceh.ac.uk
The objective of the CONFIDENCE project's Work Package 3 (WP3) was to improve the capabilities of radioecological models used to predict activity concentrations in terrestrial foodstuffs and to better characterise, and where possible, reduce uncertainties. The work programme addressed key challenges identified in the Radioecology ALLIANCE Strategic Research Agenda (Hinton et al., 2013) and specifically those of the Human Food Chain Roadmap ${ }^{1}$.

The work programme of CONFIDENCE WP3 had three over-arching and interlinked tasks:

- improving models:

- characterise and analyse the underlying probability distribution functions (PDFs) associated with transfer parameters to better enable uncertainty/sensitivity analyses,

- conduct targeted field ${ }^{131} \mathrm{I}$ tracer studies on the plantanimal-milk pathway,

- characterise the behaviour of radionuclides in Mediterranean production systems (including seasonality and key regional produce),

\footnotetext{
${ }^{1}$ https://radioecology-exchange.org/sites/default/files/T1_WG_for\% 20Radioecology\%20Roadmap_Human\%20Food\%20Chain_ver sion02022015.pdf
} 
- consider how recent knowledge would change/improve terrestrial food and dose module predictions,

- learn from post-Fukushima experiences,

- evaluate the application of extrapolation approaches (phylogeny, allometry, stable elements [see Beresford et al., 2016]) to improve predictive ability for poorly studied radionuclides;

- can process-based models reduce uncertainties?:

- determine why existing process-based approaches for Cs gave poor predictions after the Fukushima releases,

- investigate the applicability of process-based Cs model to European soil types (focusing on soil types not included in model parameterisation/validation studies),

- investigate process-based model options for $\mathrm{Sr}$,

- assess the added value of using processed based models,

- investigate how (spatial and temporal) process-based models can be incorporated into decision support systems (DSS);

- including radioactive particles in radioecological models:

- incorporate radioactive (or "hot") particles into models to improve predictions.

Results from the work programme can be found in a number of deliverable reports (Almahayni et al., 2019a; Beresford et al., 2019; Brown et al., 2018; Guillén, 2019; Lind et al., 2019) available from https://concert-h2020.eu/en/ Publications. In this paper, we give an overview of key findings and make recommendations based upon the work programme and consultations with end-users.

\section{Key findings} below.

The key findings of WP3 are highlighted and discussed

\subsection{Incorporation of the FDMT model into a flexible modelling platform (ECOLEGO)}

The FDMT model is the food chain transfer module of the JRODOS and ARGOS decision support systems (Müller et al., 2004; Brown et al., 2018). ECOLEGO is a modelling platform for creating dynamic models and performing deterministic or probabilistic simulations (Avila et al., 2005; http://ecolego. facilia.se/ecolego/show/HomePage). The software incorporates powerful numerical solvers for complex and dynamic systems (i.e. solver for ordinary differential equations including "stiff" problems) and provides support for probabilistic simulations using Monte Carlo or Latin Hypercube sampling. Incorporating FDMT into ECOLEGO (hereafter referred to as the "FDMT-ECOLEGO model") allowed us to conduct sensitivity analyses (Brown et al.. 2018), investigate regionalisation (Brown et al., 2018; Beresford et al., 2019) and replace the default model components with process-based models (discussed below) for soil-plant transfer (Almahayni et al., 2019a; Beresford et al., 2019) and the presence of radioactive particles in soil (Lind et al., 2019).

\subsection{Development and assessment of soil-plant transfer process-based models}

Commonly used models to predict radionuclide activity concentrations in human foodstuffs tend to use empirical soilto-plant transfer factors (also known as soil-plant concentration ratios) to describe the transfer of radionuclides from soil to crops (e.g. Brown and Simmonds, 1995; Brown et al., 2018). Such models cannot easily cope with variation in root uptake caused by variation in soil properties (e.g. Bogdevitch et al., 2002; Panov et al., 2009). Process-based models offer an alternative, which take into account soil (and potentially plant) characteristics.

\subsubsection{Development of process-based soil-plant models for $\mathrm{Sr}$}

The Chernobyl accident highlighted that some areas may be more "sensitive" or "vulnerable" (e.g. have comparatively high transfers to foodstuffs or contribute relatively high fluxes of radionuclides to the public via contaminated foodstuffs) to radiological contamination than other areas (e.g. see Howard et al., 2002). This lead to the development of process-based soil-plant models that were parameterised using commonly characterised soil parameters (see Almahayni et al., 2019b). However, the development of such models was restricted to radiocaesium (see below). We have developed two processbased approaches for predicting soil-plant transfer of Sr. One of these models was based upon adaptation (and simplification) of an established chemical speciation model (Tipping et al., 2011), the other requires simply a ${ }^{90} \mathrm{Sr}$ concentration in soil and the Ca concentrations in soil and crop(s) of interest (Almahayni et al., 2019a). The models gave predictions of $\mathrm{Sr}$ concentrations in a range of crops grown on different soil types (Barnett et al., 2019b) which were in considerably better agreement with measured data $\left(\mathrm{R}^{2}>0.67\right)$ than prediction using traditional empirical plant-soil concentration ratios $\left(\mathrm{R}^{2}=0.11\right)$ (Almahayni et al., 2019a). Currently these models give equilibrium predictions; consideration is needed to their incorporation, after further testing and validation, into models making dynamic predictions. To support the application of the developed models a dataset containing $\mathrm{Ca}$ concentrations in a range of crops has been established (Chaplow et al., submitted). A demonstration of the application of one of the $\mathrm{Sr}$ process-based models to a deposition scenario (De Vries et al., 2019) can be found in Brown et al. (2020).

\subsubsection{Assessment of the strengths and weaknesses of the "Absalom" process-based soil-plant model for Cs}

In Almahayni et al. (2019b), we reviewed soil-pant transfer modelling approaches for radiocaesium and concluded that the process-based model initially described by Absalom et al. (1999) was practical, robust and fit for purpose. However, predictions using this model had been shown to be relatively poor for some crops and/or non-European soils (Almahayni et al., 2019a). 
To further test the "Absalom" model (as described in Absalom et al., 2001) we determined radiocaesium transfer to grass, radish (edible root) and spinach from 20 arable and pasture soils collected from Norway, Belgium, the UK and Spain. The soils covered a range of $\mathrm{pH}$ values, organic matter contents, clay contents, CEC (cation exchange capacity) and RIP (radiocaesium interception potential) values. The transfer of radiocaesium to plants in our studies varied by up to three orders of magnitude across soil-plant combinations.

The Absalom model predicted the radiocaesium transfer to grass and radish edible root relatively well (predictions were mostly within an order of magnitude of the measurements). However, predictions for spinach were relatively poor. We recommend expanding the Absalom model database by considering more soils (with different mineralogies) and plant types in its parameterisation.

The Absalom model was implemented within the FDMTECOLEGO model and Brown et al., (2020) discusses its application to a scenario case study.

\subsubsection{Recommendation on when to use process-based soil-plant models}

As already noted, in Brown et al. (2020) we demonstrate the application of soil-plant process-based models for Cs and $\mathrm{Sr}$ to the scenario as described by De Vries et al. (2019) (an accidental release from a nuclear power plant). The models were run for five diverse, though not extreme, soils; the default FDMT model was run for comparison. At the end of the prediction period (c. 27 years after deposition) there was approaching three-orders of magnitude difference between the minimum and maximum predicted ${ }^{137} \mathrm{Cs}$ activity concentration in milk; for ${ }^{90} \mathrm{Sr}$ the difference was nearly one-order of magnitude. However, over the first six months after deposition predictions for most soil types were generally similar and also similar to predictions using FDMT default parameters; the only exception were predictions for an organic soil $(68 \%$ organic matter) and ${ }^{137} \mathrm{Cs}$ for which predictions were approaching an order of magnitude higher than FDMT after 90 days.

We recommend that in the short-term, process-based soilplant models for $\mathrm{Cs}$ and $\mathrm{Sr}$ will generally give little added benefit, i.e. models such as FDMT are sufficient for predictions during this phase (because soil-plant transfer contributes little to radionuclide activity concentrations of crops in the shortterm). However, longer-term predictions made using FDMT, or similar models, during the early phase after a deposition event should be communicated with care. Process-based models should be used to make longer-term predictions, and identify potentially vulnerable areas, once spatial predictions of deposition are available.

\subsection{Development of a model for radioactive particle behaviour in the soil plant system}

Following severe nuclear events, radioactive particles maybe released into the atmosphere and deposited in the environment (e.g. Kashparov et al., 2018). A bespoke compartmental model was conceptualised based upon an understanding of particle characteristics and behaviour, based on comprehensive particle archives and associated databases
(Lind et al., 2019). Parameters, such as those describing particle weathering rates and leaching rates from soils containing particles were derived from laboratory and field experiments. The model parameterisation of $U$ fuel particle weathering rates, which strongly depends on soil $\mathrm{pH}$ and solidstate speciation of the carrying matrix (i.e., oxidized or nonoxidized $\mathrm{UO}_{2}$ fuel particles, or $\mathrm{U}$ transformed to extra inert forms such as $\mathrm{UZr}_{\mathrm{x}} \mathrm{O}_{\mathrm{y}}$ ) was based on extensive datasets from the Chernobyl exclusion zone. The developed particle-soil model was then implemented into the FDMT-ECOLEGO model replacing the default soil radionuclide transfer models (Lind et al., 2019).

Running the revised model (including comparison with data from close to the Chernobyl exclusion zone) suggested that in the short term following an accidental release, accounting for the potential presence of radioactive particles in the soil is unlikely to be critical (ingestion dose rates, from the soil-plant pathway may be overestimated if particles are not taken into account during this phase). In the longer term (decades), not accounting for particles in the deposit may underestimate ${ }^{137} \mathrm{Cs}$ and ${ }^{90} \mathrm{Sr}$ transfer to food products (Lind et al., 2019).

\subsection{Assessment of phylogenetic models for crops and $\mathrm{Cs}$ and $\mathrm{Sr}$}

For approaching 20 years, it has been suggested that "phylogenetic relationships" offer a scientifically supported extrapolation approach to determining radionuclide activity concentrations in plants (e.g. see Willey, 2010). However, to our knowledge, the ability of the approach to predict radionuclide activity concentrations in crops has never been tested. We tested published phylogenetic relationships for Cs (Beresford and Willey, 2019) and Sr (Willey and Fawcett, 2006) using data from a plant growth study considering a range of soils and crops (Barnett et al., 2019b). Predictions were generally acceptable (within an order of magnitude of measured values) with the exception of those for $\mathrm{Sr}$ transfer to fruits/tubers. This is likely because the original phylogenetic relationships were established using measurements for shoots and not fruits/tubers.

\subsection{Radionuclide biological half-lives for farm animal products}

Many predictive models use biological half-lives (or rate constants derived from them) to describe the rate of loss of radionuclides from animal tissues and products (e.g. Müller and Pröhl, 1993; Brown and Simmonds, 1995). However, whilst there have been international compilations of transfer parameters for modelling purposes (e.g. IAEA, 2010), these have not considered biological half-life values. To address this, we have conducted a review of biological half-life values for farm animal products (meat, milk, eggs, etc.) and compiled a dataset of quality-controlled entries. The final dataset contains over 600 entries for 12 animal types (cattle, sheep, goats, deer, geese, hens, horses, pigs, rabbits, camels, ducks and red grouse) for 33 elements relevant to radiological protection. Entries include values for milk, muscle (meat), eggs, whole body, carcass and various tissues (e.g. liver and kidney). 
The dataset has been published (Barnett et al., 2019a) and will be used to make recommendations in a future publication.

\subsection{Regionalisation}

Regionalisation has been considered in two ways:

- variation of largely non-radiological parameters within the FDMT-ECOLEGO model to better match specific regions of Europe (for the purposes of demonstration these were Norway and Spain);

- the collection of transfer parameter data for Mediterranean systems.

Discussion of the effect of replacing model default parameters with regional values, for instance for animal diets, animal slaughter times, crop harvest time, productivity, can be found in Brown et al. (2018) and Beresford et al. (2019). The magnitude and temporal development of the radionuclide activity concentrations in foodstuffs are seasonally dependent and hence using regionally appropriate parameters, such as harvest dates, can impact considerably on the predicted transfer of radionuclides to the human diet.

Compilations of radionuclide transfer parameters for the human food chain (e.g. IAEA, 2010) are dominated by data for temperate ecosystems. With respect to Europe, data are sparse for Mediterranean ecosystems. Guillén (2019) discusses the sampling of wheat, triticale, grapes (including wine), olives (including olive oil), lamb, beef, pork and dairy products from sheep, goats and cows from throughout Spain. The resultant data were used to derive transfer parameters for Mediterranean production systems.

\subsection{I-131 tracer studies on the plant-animal-milk pathway}

In the early phase of an emergency situation, ${ }^{131} \mathrm{I}$ is one of the most important radionuclides for which information on contamination of human foodstuffs is essential. There is also the potential for economic and societal consequences from the loss of crops that are vulnerable to contamination, particularly those with a short harvest to market window, such as leafy vegetables, soft fruits or new potatoes.

\subsubsection{Field plant studies}

Field tracer experiments using ${ }^{131} \mathrm{I}$ have been carried out at two sites in Norway: a coastal site with high sea salt and stable iodine deposition, and an inland site with low salt and iodine deposition. Iodine-131 was sprayed onto plots on which different standing crops (grass, barley, strawberry and potato) were growing.

Results showed that ${ }^{131} \mathrm{I}$ concentrations in grass and barley at both sites were dominated by interception and changes in biomass, with little wash-off from plant to soil. There was also no discernible soil to grass transfer and no effect of stable I on vegetation activity concentrations. These results support previous studies on the importance of biomass on ${ }^{131} \mathrm{I}$ interception, but also demonstrate that changes in plant concentrations after a deposition can be adequately modelled by biomass changes. Results for potato and strawberry plants showed a small, but measurable transfer of ${ }^{131} \mathrm{I}$ from leaves to tubers and from leaves/flowers to fruit three weeks after spraying (leaves/flower to fruit/tuber concentration ratio of $<0.02$ and $<0.10$, by fresh mass (FM), respectively).

\subsubsection{The influence of protein source on the transfer of I- 131 to milk}

Results from a study in which cows were administered ${ }^{131} \mathrm{I}$ showed that rapeseed (which contains goitrogens) in the diet resulted in lower ${ }^{131}$ I activity concentrations in milk as a consequence of reduced transfer of ${ }^{131}$ I from blood to milk; there was increased excretion of ${ }^{131} \mathrm{I}$ via urine.

\section{Recommendations}

We present recommendations based upon the outcomes of our work programme as discussed above and reported in various deliverables (Almahayni et al., 2019a; Beresford et al., 2019; Brown et al., 2018; Guillén, 2019; Lind et al., 2019). We also present recommendations from a joint workshop (September 2019) organised by CONFIDENCE WP3 in association with the Radioecology ALLIANCE Human Food Chain Working Group. The recommendations and findings from CONFIDENCE WP3 have helped to revise the Strategic Research Agenda (SRA) for radioecology (Salomaa, 2019).

\subsection{Recommendations for future research arising from CONFIDENCE studies}

The following recommendations are based upon the work we conducted within CONFIDENCE WP3:

- soil-plant process-based models are worth pursuing for Cs and $\mathrm{Sr}$;

- the "Absalom" process-based model for Cs soil-plant transfer needs to be tested, and potentially adapted, for a wider range of crops grown on a variety of soil types with differing mineralogies;

- the soil-plant process-based models developed by CONFIDENCE for $\mathrm{Sr}$ need further validation and testing; consideration needs to be given on how to incorporate the models into dynamic food chain models such as FDMT in JRODOS and ARGOS;

- how to use the potential ability of soil-plant process-based models to model the effect of soil based countermeasures (namely K-fertilisation and liming) needs to be better considered and included into DSS;

- scientists need to clearly make the case for using processbased models in post-accident management and be clear when they would be useful; training (appropriate to specific audiences) in the use of process-based models needs to be developed and provided;

- there is a need to include uncertainties in models and their outputs. This work has been started in CONFIDENCE WP3 for the FDMT in ECOLEGO model, but further work is needed to expand the statistical data collation to parameters not originally covered and to consolidate the information for those parameters that have been considered; 
- further work is needed to perform a global sensitivity analysis and investigate the correlation between parameters. Discussion is required on how ignoring interdependency of variables in a model can contribute to uncertainty. This may provide a deeper understanding of the model behaviour by interpreting the dependency and interaction pattern;

- it is recommended that FDMT parameters be updated. Greater transparency should be provided where parameters have to be extrapolated because data are lacking; where data are lacking experimental work should be encouraged;

- there is a need to consider deposition, interception and retention of radioactive particles, all processes which are likely to be important in the early stages (weeks and months) post-accident; such evaluations should also consider the potential for animals (and humans) to ingest radioactive particles;

- phylogenetic models, which allow predictions to be made for a wide range of crops for a given site without the need for soil type specific studies, need to be validated and where required, parameterised using the component of plants consumed;

- the application of transfer parameters derived from stable elements in radioecological models need to be further reviewed (see Beresford et al., 2019);

- transfer parameters are required for some regionally important agricultural products in Europe (e.g. nuts, rice, sunflower products) (though to some extent if taken forward phylogenetic and potentially soil-plant processbased models [for Sr at least] may negate the need for some data collection).

\subsection{Future priorities for human food chain radioecological studies from end-user consultation}

In September 2019, CONFIDENCE WP3 held a joint workshop with the Radioecology ALLIANCE (Beresford et al., 2019). The approximately 40 participants included representatives from regulatory bodies, industry, governmental agencies and the IAEA. The aim of the workshop was to identify future priorities for radioecological research with respect to the human food chain; discussions are summarised below (see Beresford et al., 2019 for further information).

\subsubsection{Radionuclides}

There was wide agreement that data on some radionuclides was poor and that some emphasis should be given to providing data and/or recommending modelling approaches. Radionuclides highlighted included:

- those released by medical facilities for which data are poor or often totally lacking (e.g. radioisotopes of $\mathrm{Cr}, \mathrm{F}, \mathrm{Fe}, \mathrm{Ga}$, Ho, In, La, P, Re, Sm, Tc, etc.);

- radionuclides associated with the decommissioning of nuclear licenced sites (including, ${ }^{108,108 \mathrm{~m}} \mathrm{Ag},{ }^{243} \mathrm{Am},{ }^{10} \mathrm{Be}$, ${ }^{41} \mathrm{Ca},{ }^{152,154,155} \mathrm{Eu},{ }^{55,59} \mathrm{Fe},{ }^{203} \mathrm{Hg},{ }^{93} \mathrm{Mo},{ }^{22} \mathrm{Na},{ }^{93 \mathrm{~m}} \mathrm{Nb}$, ${ }^{147} \mathrm{Nd},{ }^{93 \mathrm{~m}} \mathrm{Nb},{ }^{193} \mathrm{Pt},{ }^{46} \mathrm{Sc},{ }^{151} \mathrm{Sm}$ and $\left.{ }^{182} \mathrm{Ta}\right)$;

- radionuclides relevant to fusion reactors (including activation products such as radionuclides of $\mathrm{Ag}, \mathrm{Fe}, \mathrm{Mn}$, $\mathrm{Nb}, \mathrm{Ni}, \mathrm{Tb}$ in addition to focussing on ${ }^{3} \mathrm{H}$ ); long-lived radionuclides associated with geological disposal facility assessments.
It was noted that requirements for data for many of these radionuclides was not only restricted to the human food chain, but also to the need for parameters for biota assessments. In some instances, it is likely that doses to the public through food consumption (and also doses to biota) will be low from some of these radionuclides (short-lived radioisotopes discharged from medical facilities likely being an example). However, assessments have to be conducted by industry/regulators to assess the potential impact of these radionuclides. Therefore, we need to advise on how best to conduct these assessments such that they are fit for purpose and proportionate. A scoping study on how best to address this need is required as a first step.

\subsubsection{Regionalisation}

There is a need to take into account potential regional variation in radionuclide transfer and also regional variation in diet and farming practices, including seasonality (e.g. in northern Europe farm stock are fed stored forage in winter, in southern Europe stored forage may be fed in summer) (Brown et al., 2018; Beresford et al., 2019). Radionuclide transfer data in compendia such as IAEA $(2010,2014)$ are biased towards temperate systems. Data are also lacking for what were termed "exotic foodstuffs" which, in some instances, may be regionally important (e.g. snails, dates, wine). There is also a need to consider our ability to predict radionuclide behaviour under changing climate scenarios. CONFIDENCE WP3 and other recent work have made a step to providing radioecological data for Mediterranean ecosystems (Guillén et al., 2018, 2019; Guillén, 2019).

\subsubsection{Novel foodstuff and changing agricultural practices}

Our diets and agricultural practices evolve continually with different (potentially new to Europe or a given country) foods gaining popularity (chia and quinoa would be relatively recent examples, with interest in insect based foods for farm livestock and humans currently increasing [e.g. van Huis et al., 2013]). The workshop recommended that we need to ensure our models (and underlying data) keep up with changes in diet and foodstuffs. To some degree, "phylogeny-based" extrapolation approaches and/or some process-based models may help us to derive radionuclide transfer parameters for novel foodstuffs. With respect to agricultural production, it was noted that satellite data could be used to identify agricultural production (what crop is grown where and when) and to estimate crop yields (e.g. https://www.ceh.ac.uk/crops2015).

\subsubsection{Innovative ways of providing transfer parameters}

In reality, the number and diversity of radionuclides and foodstuffs (and for biota assessments, wildlife species) means that, we are never going to have data for everything. In some ways, clear acknowledgement of this, and the consideration of open and robust extrapolation approaches, has progressed further for biota/wildlife models (e.g. Brown et al., 2013; Beresford et al., 2016) than for human food chain models. There was general support for the use of phylogenetic models (as discussed above) with the recommendations that the models needed to be for the plant parts consumed and that more rigorous testing was required. It was also suggested that 
the phylogenetic approach could be a useful "add-on" to process-based models, which have been parameterised for radionuclide transfer to grass (e.g. see discussion in Almahayni et al., 2019a).

Ionomics and/or ecological stoichiometry were also suggested as scientifically based extrapolation approaches, whereby similarities in the behaviour of some elements/ radionuclides could be used to make predictions of radionuclide activity concentrations in foodstuffs (or biota) (e.g. $\mathrm{Sr}$ predictions based on Ca data would be an example). Whilst this has been suggested previously (see Beresford et al., 2016) to date little progress has been made.

For farm animals, it was recommended that there should be a move away from the transfer coefficient (defined as the ratio of the radionuclide activity concentration in an animal derived foodstuff to the daily intake of the radionuclide) towards using the dietary concentration ratio (i.e. the ratio of the radionuclide activity concentration in an animal derived foodstuff to that in its diet [on a dry matter basis]) instead. Concentration ratios for one animal can be used with some confidence for other animals (farm livestock and potentially wildlife) for which data are lacking (see discussion in Beresford et al., 2016).

Well-founded extrapolation approaches will also help us to address the lack of data for many radionuclides and the need to upkeep parameter databases/models to account for novel foodstuffs.

\subsubsection{Foliar uptake}

There was general recognition that radionuclide interception by plants and subsequent retention and translocation has received relatively little attention. The lack of relevant data was highlighted after the Fukushima accident with unexpected transfer of radiocaesium to fruit being reported (e.g. Sato et al., 2015).

\subsubsection{Remediation}

There was discussion of the work of Penrose et al. (2015, 2016, 2017) on the selection of plant varieties with low radionuclide uptake. It was noted that in the event of any future accident, low accumulating varieties could be identified relatively quickly by collaborating with the many worldwide plant-breeding programmes. There was also the suggestion that CRISPR (clustered regularly interspaced short palindromic repeat; Wang et al., 2019) technology could be used produce crops with low uptakes. However, there are socio-political challenges associated with CRISPR technology as it may be considered as genetic modification of organisms.

There were recommendations that modelling approaches to improve the assessment of soil based countermeasures were needed, which links to the recommendation above that we need to better exploit the potential ability of process-based models to consider the effect of soil based countermeasures.

\subsubsection{Radioecological models}

In addition to the specific recommendations above, the needs to communicate radioecological models to end-users and to ensure model validation were stressed. Users (regulators, governmental agencies and ministries) need to have confidence in the outputs of the models at their disposal. The example was given of the lack of confidence of Japanese authorities to use predictions from the Japanese government's System for Prediction of Environmental Emergency Dose Information (SPEEDI) in the management of the postFukushima situation (see Funabashi and Kitazawa, 2012).

Model validation would benefit from participation in programmes such as those organised by the IAEA (e.g. MODARIA II follow-on ${ }^{2}$ ).

Other comments on radioecological models were:

- the need to include uncertainties in models and their outputs;

- lack of consideration of the presence of other contaminants;

- parameterise models with parameters which are readily available or relatively easy to determine;

- predictive models should be linked to monitoring data, such that the monitoring data can be used to refine assessments;

- the need to consider the societal consequence of models being wrong and/or over-conservative.

Acknowledgements. We thank all of our colleagues who have contributed to the delivery of our work programme. Our thanks also go to all the attendees of the workshop held in Madrid in September 2019 whose discussions contributed to this paper. The work described in this paper was conducted within the CONFIDENCE project, which was part of the CONCERT project. The CONCERT project received funding from the Euratom Research and Training programme (2014-2018) under grant agreement No. 662287.

Disclaimer (Art. 29.5 GA). This publication reflects only the author's view. Responsibility for the information and views expressed therein lies entirely with the authors. The European Commission is not responsible for any use that may be made of the information it contains.

\section{References}

Absalom JP, Young SD, Crout NMJ, Nisbet AF, Woodman RFM, Smolders E, Gillett AG. 1999. Predicting soil to plant transfer of radiocaesium using soil characteristics. Environ. Sci. Technol. 33: 1218-1223. https://doi.org/10.1021/es9808853.

Absalom JP, Young SD, Crout NMJ, Sanchez A, Wright SM, Smolders E, Nisbet AF, Gillett AG. 2001. Predicting the transfer of radiocaesium from organic soils to plants using soil characteristics. J. Environ. Radioact. 52: 31-43. https://doi.org/10.1016/ S0265-931X(00)00098-9.

Almahayni T, Sweeck L, Beresford NA, Barnett CL, Lofts S, Hosseini A, Brown J, Thørring H, Guillén J. 2019a. An evaluation of process-based models and their application in food chain assessments. CONCERT Deliverable D9.15. https://concerth2020.eu/en/Publications.

Almahayni T, Beresford NA, Crout NMJ, Sweeck L. 2019b. Fit-forpurpose modelling of radiocaesium soil-to-plant transfer for nuclear emergencies: a review. J. Environ. Radioact. 201: 58-66. https://doi.org/10.1016/j.jenvrad.2019.01.006.

\footnotetext{
${ }^{2}$ https://www-ns.iaea.org/projects/modaria/
} 
Avila R, Broed R, Pereira A. 2005. ECOLEGO - A toolbox for radioecological risk assessment. In: Proceedings of the International Conference on the Protection from the Effects of Ionizing Radiation, IAEA-CN-109/80. pp. 229-232. Stockholm: International Atomic Energy Agency.

Barnett CL, Wells C, Fesenko S, Tagami K, Beresford NA. 2019a. Radionuclide biological half-lives for farm animals. NERCEnvironmental Information Data Centre. https://doi.org/10.5285/ d26ea56a-a692-427c-8f5a-a9bb6eb7da6b.

Barnett CL, Wells C, Beresford NA, Guillén J, Gómez Polo FM, Thacker S, Lawlor AJ, Keenan PO. 2019b. Elemental concentrations (Ca, Cs, $\mathrm{K}, \mathrm{Mg}, \mathrm{Sr}$ ) in a range of crops and associated soils from the UK and Spain. NERC Environmental Information Data Centre. https://doi.org/10.5285/76d6772d-477e-4a49-a4a6a0fe6a0a9ba9.

Beresford NA, Willey N. 2019. Moving radiation protection on from the limitations of empirical concentration ratios. J. Environ. Radioact. 208-209: 106020. https://doi.org/10.1016/j.jenv rad.2019.106020.

Beresford NA, Wood MD, Vives i Batlle J, Yankovich TL, Bradshaw C, Willey N. 2016. Making the most of what we have: application of extrapolation approaches in radioecological wildlife transfer models. J. Environ. Radioact. 151: 373-386. http://dx.doi.org/ 10.1016/j.jenvrad.2015.03.022.

Beresford NA, Barnett CL, Brown JE, Hosseini A. 2019. CONFIDENCE overview of model improvements and future needs. CONCERT Deliverable D9.17. https://concert-h2020.eu/en/Pub lications.

Bogdevitch I, Tarasiuk S, Shmigelskaya I, Putyatin Y. 2002. Soil fertility influence on ${ }^{137} \mathrm{Cs}$ and ${ }^{90} \mathrm{Sr}$ transfer to the crops. Radioprotection 37: 485-490. https://doi.org/10.1051/radiopro/ 2002090.

Brown J, Simmonds JR. 1995. FARMLAND A dynamic model for the transfer of radionuclides through terrestrial food chains. NRPBR273. Didcot: National Radiological Protection Board. https:// www.phe-protectionservices.org.uk/cms/assets/gfx/content/ resource_4246cs69295f5f6b.pdf.

Brown JE, Beresford NA, Hosseini A. 2013. Approaches to providing missing transfer parameter values in the ERICA Tool - How well do they work? J. Environ. Radioact. 126: 399-411. http://dx.doi. org/10.1016/j.jenvrad.2012.05.005.

Brown JE, Avila R, Barnett CL, Beresford NA, Hosseini A, Lind O-C, Oughton DH, Perez D, Salbu B, Teien HC, Thørring H. 2018. Improving models and learning from post-Fukushima studies. CONCERT Deliverable D9.13. https://concert-h2020.eu/en/Pub lications.

Brown JE, Beresford NA, Hosseini A, Barnett CL. 2020. Applying process-based models to the Borssele scenario. Radioprotection 55(HS1). https://doi.org/10.1051/radiopro/2020020.

Chaplow J, Beresford NA, Barnett CL. Submitted. Calcium and magnesium concentrations in plants used as human and animal foods derived from global literature. NERC Environmental Information Data Centre.

De Vries H, Geertsema G, Korsakissok I, Périllat R, Scheele R, Tomas J, Andronopoulos S, Astrup P, Bedwell P, Charnock T, Hamburger T, Ievdin I, Leadbetter S, Pázmándi T, Rudas C, Sogachev A, Szántó P, Wellings J. 2019. Published sets of probability maps of threshold exceedance for scenarios provided to WP4, WP 5 \& WP6 $\rightarrow$ 2. CONCERT Deliverable D9.4. https://concert-h2020.eu/en/ Publications.

Funabashi Y, Kitazawa K. 2012. Fukushima in review: a complex disaster, a disastrous response. Bull. At. Sci. 68: 9-21. http://dx. doi.org/10.1177/0096340212440359.
Guillén J. 2019. Published dataset on transfer in Mediterranean ecosystems. CONCERT Deliverable D9.14. https://concert-h2020. eu/en/Publications.

Guillén J, Baeza A, Izquierdo M, Beresford NA, Wood MD, Salas A, Muñoz-Serrano A, Corrales-Vázquez JM, Muñoz-Muñoz JG. 2018. Transfer parameters for ICRP's Reference Animals and Plants in a terrestrial Mediterranean ecosystem. J. Environ. Radioact. 186: 9-22. https://doi.org/10.1016/j.jenv rad.2017.06.024

Guillén J, Gómez Polo FM, Baeza A, Ontalba MA. 2019. Transfer parameters for radionuclides and radiologically significant stable elements to foodstuffs in Spain. NERC-Environmental Information Data Centre. https://doi.org/10.5285/48d5395e-e9fb-45edb69f-1ea0d2d36be6.

Hinton TG, Garnier-Laplace J, Vandenhove H, Dowdall M, AdamGuillermin C, Alonzo F, Barnett C, Beaugelin-Seiller K, Beresford NA, Bradshaw C, Brown J, Eyrolle F, Fevrier L, Gariel J-C, Gilbin R, Hertel-Aas T, Horemans N, Howard BJ, Ikäheimonen T, Mora JC, Oughton D, Real A, Salbu B, SimonCornu M, Steiner M, Sweeck L, Vives i Batlle J. 2013. An invitation to contribute to a strategic research agenda in radioecology. J. Environ. Radioact. 115: 78-82. http://dx.doi. org/10.1016/j.jenvrad.2012.07.011.

Howard BJ, Strand P, Assimakopoulos P, Bréchignac F, Gascó C, Métivier H, Moberg L, Smith JT, Tamponnet C, Trueba C, Voigt G, Wright S. 2002. Estimation of radioecological sensitivity. Radioprotection 37: 1167-1173. http://dx.doi.org/10.1051/radio pro/2002142.

van Huis A, van Itterbeeck J, Klunder H, Mertens E, Halloran A, Muir G, Vantomme P. 2013. Edible insects: future prospects for food and food security. FAO Forestry Paper 171. Rome: FAO. http:// www.fao.org/3/i3253e/i3253e.pdf.

IAEA. 2010. Handbook of parameter values for the prediction of radionuclide transfer in terrestrial and freshwater environments. Technical Reports Series No. 472. Vienna: IAEA. https://wwwpub.iaea.org/MTCD/publications/PDF/trs472_web.pdf.

IAEA. 2014. Handbook of parameter values for the prediction of radionuclide transfer to wildlife. Technical Reports Series No. 479. Vienna: IAEA. http://www-pub.iaea.org/MTCD/Publica tions/PDF/Trs479 web.pdf.

Kashparov V, Levchūk S, Zhurba M, Protsak V, Khomutinin YU, Beresford NA, Chaplow JS. 2018. Spatial datasets of radionuclide contamination in the Ukrainian Chernobyl Exclusion Zone. Earth Syst. Sci. Data 10: 339-353. https://doi.org/10.5194/essd10-339-2018b.

Lind O-C, Brown J, Hosseini A, Salbu B, Kashparov V, Beresford NA. 2019. Evaluation of the importance of hot particles in radioecological models. CONCERT Deliverable D9.16. https:// concert-h2020.eu/en/Publications.

Müller H, Pröhl G. 1993. ECOSYS-87: a dynamic model for assessing radiological consequences of nuclear accidents. Health Phys. 64: 232-252. https://doi.org/10.1097/ 00004032-199303000-00002.

Müller H, Gering F, Pröhl G. 2004. Model description of the terrestrial food chain and dose module FDMT in RODOS PV 6.0. RODOS(RA3)-TN(03)06. Report version 1.1. https://resy5.iket. kit.edu/RODOS/Documents/Public/HandbookV6/Volume3/ FDM_Terra.pdf.

Panov AV, Alexakhin RM, Prudnikov PV, Novikov AA, Muzalevskaya AA. 2009. Assessment of countermeasure effects on ${ }^{137} \mathrm{Cs}$ accumulation from soil by farm crops after the accident at the Chernobyl NPP. Radioprotection 44: 897-902. https://doi.org/ 10.1051/radiopro/20095160. 
Penrose B, Beresford NA, Broadley M, Crout NMJ. 2015. Intervarietal variation in caesium and strontium uptake in plant: a metaanalysis. J. Environ. Radioact. 139: 103-117. http://dx.doi.org/ 10.1016/j.jenvrad.2014.10.005.

Penrose B, Johnson née Payne KA, Arkhipov A, Maksimenko A, Gaschak S, Meacham MC, Crout NJM, White PJ, Beresford NA, Broadley MR. 2016. Inter-cultivar variation in soil-to-plant transfer of radiocaesium and radiostrontium in Brassica oleracea. J. Environ. Radioact. 155-156: 112-121. http://dx.doi.org/ 10.1016/j.jenvrad.2016.02.020.

Penrose B, Beresford NA, Crout NM, Lovatt JA, Thompson R, Broadley MR. 2017. Forage grasses with lower uptake of caesium and strontium could provide 'safer' crops for radiologically contaminated areas. PLoS One 12: e0176040. https://doi.org/ 10.1371/journal.pone.0176040.

Salomaa S. (Ed.). 2019. Updating the SRAs of MELODI, ALLIANCE, NERIS, EURADOS and EURAMED. CONCERT Deliverable D2.13. https://concert-h2020.eu/en/Publications.

Sato M, Takata D, Tanoi K, Ohstuki T, Muramatsu Y. 2015. Radiocesium transfer into the fruit of deciduous fruit trees contaminated during dormancy. J. Soil Sci. Plant Nutr. 61: 156164. https://doi.org/10.1080/00380768.2014.975103.

Tipping E, Lofts S, Sonke JE. 2011. Humic Ion-Binding Model VII: a revised parameterisation of cation-binding by humic substances. Environ. Chem. 8: 225-235. https://doi.org/10.1071/ EN11016.

Wang T, Hongyan Z, Hongliang Z. 2019. CRISPR technology is revolutionizing the improvement of tomato and other fruit crops. Hortic. Res. 6: 77. https://www.nature.com/articles/ s41438-019-0159-x.

Willey NJ. 2010. Phylogeny can be used to make useful predictions of soil-to-plant transfer factors for radionuclides. Radiat. Environ. Biophys. 49: 613-623. https://doi.org/10.1007/ s00411-010-0320-2.

Willey N, Fawcett K. 2006. A phylogenetic effect on strontium concentrations in angiosperms. Environ. Exp. Bot. 57: 258-269. https://doi.org/10.1016/j.envexpbot.2005.06.005.

Wynne B. 1992. Misunderstood misunderstanding: social identities and public uptake of science. Public Underst. Sci. 1: 281-304. https://doi.org/10.1088/0963-6625/1/3/004.

Cite this article as: Beresford NA, Barnett CL, Chaplow J, Lofts S, Wells C, Brown JE, Hosseini A, Thørring H, Almahayni T, Sweeck L, Guillén J, Lind O-C, Oughton DH, Salbu B, Teien H-C, Sánchez DP-, Real A. 2020. CONFIDENCE overview of improvements in radioecological human food chain models and future needs. Radioprotection 55(HS1): S101-S108 